\title{
Research on Environmental Impact Prediction of Sustainable Development of Wetland Resource
}

\author{
Juan Dai, Yue Zeng*, Lingyun Li, Miao He, Xiuling He \\ Changjiang River Scientific Research Institute, Wuhan, China \\ Email:daijuan0906@sina.com
}

\begin{abstract}
Key words: Wetland Resource. Sustainable Development. Environmental Impact Prediction.
Abstract. Wetland is the richest ecosystem with diversified creatures and also is one of the most important living environments. As the irrational utilization and damage of wetland resource in recent years, wetland resource is experiencing a degenerative process. As a unique ecosystem that is different from lands and water areas, wetland plays an important positive role in the sustainable development of the society and economy. Therefore, the protection of wetland is mutual responsibility of the whole society, and also is the inner appeal to achieve sustainable development. Based on the analysis of current environmental problems of wetland resource in Zhuannanzhou, it discussed the environmental impact assessment theory of sustainable development, studied the difficulties that exist in the development of wetland resource and sustainable development, and proposed corresponding countermeasures. These countermeasures can provide beneficial suggestions for the exploration of sustainable utilization of wetland resource and promote the harmonious development of ecology, society, economy, environment, and biodiversity in the wetland, and the enrichment of theory and methods of sustainable development.
\end{abstract}

\section{Introduction}

Wetland is the richest ecosystem with diversified creatures and also is one of the most important living environments. As the irrational utilization and damage of wetland resource in recent years, wetland resource is experiencing a degenerative process. As a unique ecosystem that is different from lands and water areas, wetland plays an important positive role in the sustainable development of the society and economy. Therefore, the protection of wetland is mutual responsibility of the whole society, and also is the inner appeal to achieve sustainable development. Based on the analysis of current environmental problems of wetland resource in Zhuannanzhou, it discussed the environmental impact assessment theory of sustainable development, studied the difficulties that exist in the development of wetland resource and sustainable development, and proposed corresponding countermeasures. These countermeasures can provide beneficial suggestions for the exploration of sustainable utilization of wetland resource and promote the harmonious development of ecology, society, economy, environment, biodiversity in the wetland and the enrichment of theory and methods of sustainable development.

\section{Current Environmental Status}

Zhuannanzhou is located in the intersection of left bank of Wuhan reach and Tongshun River. In this region, there are naturally formed wetlands, abundant rainfall, and its frost-free season lasts for 250 days, as a result, Zhuannanzhou has sufficient wetland resource, dense vegetation, ample moisture and high habitat diversity. Besides, this region has varied habitats for animals like birds 
and fishes. The overall terrain of the project area is broad and flat, $80 \%$ areas are bottom lands of Changjiang and Tongshun River, and these areas have little altitude differences. The naturally formed wetland and Zhuannanzhou that has sufficient wetland resource, dense vegetation, ample moisture, high habitat diversity, varied habitats for animals like birds and fishes. However, as the continuous development of social economy, human activities in the project area have bigger influences on these natural resources and wetland resources in Zhuannanzhou has been disturbed and even damaged constantly. Some areas even suffer from serious water and soil loss. Meanwhile, the middle and lower reaches of Changjiang River including Zhuannanzhou are main epidemic areas of blood flukes disease in China that threaten the safety of production activities of local people in breeding industry and plantation.

\section{Scale of Engineering Construction}

Wetland ecological protected area. The scope of ecological protected area in the wetlands of Zhuannanzhou is delta between Dongjin River and Changjiang River, from the intersection between Dongjin River and Changjiang River in the east to cement hardened road on the westside of Xiaojun Mountain in the west, from the left bank of Changjiang River in the south to the right bank of Dongjin River in the north. The overall area is around $10.4 \mathrm{~km}^{2}$. The scope of ecological protection area in the wetlands includes reed base, fishpond, lotus pond, Xiaojun Mountain and surrounding facilities like villages or schools, as well as pond and wetland that are formed naturally.

Function Division of Wetland Protection Area. According to the characteristics of resource allocation in the ecological protection area in the wetland of Zhuannanzhou, and flood prevention requirements in flood detention area in Dujiatai, as well as the requirements on many other aspects, such as the ecological environment protection, the governance of water and soil loss, and prevention of blood flukes, function division of wetland protection area has been carried out. The ecological protection area of wetland in Zhuannanzhou will be divided into three functions based on our initial plan, namely, reserve zone for flood detention, area for the prevention of blood flukes and area for soil and water loss governance. The scope of each function area is shown below:

The first area. Flood detention area. It covers an area of $6.1 \mathrm{~km}^{2}$; it mainly is reed base that is close to the intersection of Dongjin River and Changjiang River, its upstream reaches to Huanglingjizha. The land in this region is flat and its altitude is relatively low, the average altitude is about $24 \mathrm{~m}$.

The second area. Blood flukes prevention area. It covers an area of $3.8 \mathrm{~km}^{2}$; the main parts of this area start from the upward area of Huanglingjizha to the north side of Xiaojun Mountain. The overall terrain in the region is featured as "low in the middle but high on both sides". On the east is dike of Changjiang River with the altitude around 29-31m; in the west it includes the area from Xujiabao to Mozishan in the south, it is connected with the north slope of Xiaojun Mountian, which forms a barrier that separate Dongjin River from Changjiang River, and its altitude is around 32 $42 \mathrm{~m}$. Between the two there are large areas of fish pond, lotus pond and other pond or bottomlands that formed naturally or artificially.

The third area. The area for soil and water loss governance. It covers an area of $0.5 \mathrm{~km}^{2}$. It is mainly consisted by highlands and surrounding villages in Xiaojun Mountain, and a few of fish ponds, lotus pond and lakes are located in this place. The highest mountain in this region is the top of Xiaojun Mountain and its altitude is $72.375 \mathrm{~m}$.

\section{Environmental impact prediction}

\section{Possible favorable environmental influences of the project construction.}

It creates diversified aquatic environment and terrestrial environment that can provide sufficient 
living space for animals like fish and bird and improve the current status of ecologic environment in Zhuannanzhou.

It can create diversified growing environment for plants, and meet the diversified needs for the environment of plant growth, which is beneficial to change the singular species distribution, and improve the integrality and phyletic diversification of vegetational types;

It can strengthen the function of water conservation and purification in wet land, and improves the self-purification of water. Meanwhile, through the readjustment of industrial structure in the project area, the large-scale development of ecological tourism and reduction of aquaculture industrial size can decrease the source of water contamination. Therefore, the local water quality will be improved after the project construction.

The ecology landscape and recreational function of urban wetland will be fully reflected. Therefore, it can be taken as an urban landscape after the project was completed. It can offer places for the entertainment and recreation of citizens, improve human settlement and generate good social effects.

\section{Possible Negative Environmental Influences Caused by Project Construction.}

The negative environmental influences of this project are mainly reflected in the construction. As long as the construction soil and stone as well as material equipments can be placed in accordance with the regulations and organized regularly, water loss and unfavorable effect on surrounding environment will be reduced. In the construction, a certain amount of waste water, waste gas, waste residue, noise and soil disturbance. Besides, it also will have temporary unfavorable effect on surrounding environment, including influences on ecological environment in the construction period, air pollution, water pollution, solid waste and noise pollution.

\section{Environmental Protection and Monitoring}

\section{Measures for Environmental Protection}

Ecological Protection and Expected Effects. During the project construction, we should try to reduce damaging plants during the construction. The secondary nudation (especially stockpile area) formed in project construction period should be covered with soil or planted with trees. Adjusting measures to local conditions and making full use of the favorable climate in wetlands to recover vegetation. After the completion of construction, comprehensive environmental protection measures shall be taken in the construction area based on the requirement of environmental protection, so as to green and beautify the construction environment and form a favorable ecological circulation system. Overall, a small scale of the body of water will be contaminated in the construction period, and a small part of aquatic organism will be affected. However because of the short construction time, the influences are relatively limited. After the project completion, this influence will be weakened gradually.

Water Pollution Control and Expected Effects. The disposal of excavating water: in digging fish pond or lotus pond, partitioned operation should be adopted, so as to reduce the damage to non-viscous soil layer. Centralized processing must be used for the filtered waste water in sludge, so as to prevent it from flowing into nearby rivers directly and avoid secondary pollution. The disposal of alkali wastewater: the maintenance of concrete in the project construction will generate certain amounts of alkali wastewater, while sedimentation treatment shall be used to process alkali wastewater with industrial acid.

The disposal of wastewater in mechanical equipment: because of small discharge of wastewater, dispersed construction sites and limited field, some simple and easily applied measures can be used based on actual condition, so as to reduce the emission of pollution and reduce its effect on surface water quality.

The disposal of domestic wastewater: according to the general layout of the construction, constructors and managers can rent nearly residents' houses. Similarly, the responsible person of construction design and supervision units can also rent these houses as places for production and office occupancy. Therefore, the domestic wastewater generates in the construction period can be 
discharged into existing sewage pipe network directly.

Drainage of wastewater in foundation pit: In the project construction, wastewater in foundation pit gathered because of rainfall, water seepage of cofferdam and construction water, the key pollutants are suspended solid. The drainage of wastewater in foundation pit has certain effect on the quality of partial water in the foundation pit. Sump shall be designed in the foundation pit during project construction, and use water pump to drainage waste water. When the concentration of suspended matter is too high, we should precipitate it for a while before drainage wastewater, and then we need to clean up the mud in foundation pit timely.

Air Conservation. According to national regulations related to labor protection, dustproof articles have to be distributed to on-site constructors who work at dust producing environment. In the loading and uploading and transportation of cement, cement must be transported in sealing status. When too many dusty raw materials are loaded, these raw materials must be stacked in order, so as to reduce wind area. Properly add the moisture of raw materials is needed for reducing the dust emission in transportation. The speed of vehicles that drive on the major road must be limited, and the traffic artery should be wetted with water in drought and windy season to reduce dust emission. It is suggested to reduce the emission of harmful tail gas by enhancing vehicle maintenance and using superior raw materials, and enhancing the environmental awareness of front-line operating personnel etc.

Acoustic Environment Protection. The used of high-noise equipment should be controlled, and try to use them in day time. At late night (22:00 to 06:00), high-noise equipment shall not be used for project construction. The transportation at night should use lighting as warning instead of honking the horn. Besides, the maintenance of noisy construction equipments should be strengthened. Starting with the regulation of construction order, construction time and the construction site layout should be arranged reasonably. High quality construction equipment should be used to reduce the sound level and noise. Moreover, temporary noise isolation barrier should be established to reduce noise pollution. For equipment with high noise and sound source that can't be lowered down easily in construction, sound attenuation can be used temporarily. Sound absorption material can be placed around, so as to achieve noise reduction effect.

Disposal of Solid Waste. Soil and stone waste, as well as construction waste: according to the construction progress, these can be allocated and used as filler. The spoil soil generates in construction and construction waste that are generated from demolition can't be reused for this project temporarily, but it can be taken as the basic filler and green land soil for designated construction projects of municipal administration and planning department.

Domestic waste. In the construction period, the domestic waste shouldn't be thrown randomly; it can't be thrown into the body of water, but be cleaned up and processed by environmental sanitation department in unification. After the garbage disposal, it won't have any negative effect on surrounding environment.

\section{Environmental Monitoring}

The layout of environmental monitoring station and monitoring content for the construction of ecological protection area in the wetlands of Dunnanzhou are as following.

Water quality. Layout of monitoring station: two stations locate in flood detention area, two stations locate in the prevention area of blood flukes, and one station locates in the station of water loss governance, so there are five monitoring stations in total.

Monitoring items. The index of $\mathrm{pH}$, Dissolved Oxygen, permanganate, nitrate, ammonia nitrogen, total phosphorus, coliform and fluorine etc.

Monitoring method. Monitor each index based on the methods written in the "environmental quality standards for surface water" (GB3838-2002).

Monitoring frequency. Once a time at the wet period and dry period in the construction period.

Ambient Air. Layout of monitoring station: one station locates nearby Huanglinjizha, and one 
monitoring station only in total.

Monitoring items. Total suspended particulates, sulfur dioxide and nitric oxide.

Monitoring method. The sampling frequency and monitoring method are monitored based on the regulations in the "ambient air quality standard" (GB3095-1996).

Monitoring frequency. One time before the construction, in the construction and after the construction respectively.

Noise. Layout of monitoring station: one station locates at each construction centralized area.

Monitoring items. Traffic noise and construction noise.

Monitoring method. Monitoring based on the methods in the "measurement of environmental noise in cities" (GB/T14623).

Monitoring frequency. One time before the construction, in the construction and after the construction respectively.

\section{Conclusions}

The project has significant social effect and ecological benefits, so the wetland advantages and geographical advantages in Zhuannanzhou can be fully used. After the project construction completed, the natural environment in the project area will be improved significantly, and different degree of changes can be found from ecological environment, water quality and climate in partial area. Besides, as urban wetlands, after the construction of ecological protection area in the wetlands of Zhuannanzhou, it can be regarded as important locations for ecological tourism and recreation. Meanwhile, it can also improve the livability and promote the development of ecological Wuhan.

Although the project construction has certain negative effect on environment, its negative effect is weak, and acceptable. After the construction of anti-pollution measures, the negative environmental impact will be reduced to the lowest level.

Environmental management measures are suggested to take. Environmental protection measures stipulated in this report shall be strictly followed during the construction and operation period, environmental investment will be implemented, and regular monitoring is needed. Meanwhile, supervision by public opinions shall also be fully played.

\section{References}

[1] Yu Muqing, Tianwei, Liu Jingshuang, Zhu Yanming, Sun Daowei, Primary Study on Wetland Resources Conservation and Their Sustainable Utilization in Xianghai National Nature Reserve. Geographical Science; 2000(2).

[2] Zhang Hongcheng, Yang Yong, Dai Qigen, Hu Xiaojun; Discussion on the Agriculture in the Wetland of the Lower Reaches of Yangtze River and Its Development; Jiangsu Agricultural Sciences 2004(4).

[3] Zhang Guangxin, Deng Wei, Song Xinshan, Study of the Sustainable Utilization of Wetland Resource in the West of Jinlin; Environmental Protection; 2001(1).

[4] Xiang Gui'e, Wang Kaifeng; Research on Protection and Sustainable Utilization of Wetland Resource in Shengjin Lake; Territory \& Natural Resources Study;2005(1).

[5] Wu Haitao, Lv Xianguo; Research Progress and Expectation on the Evaluation of Wetland in China; World Forestry Research; 2005(4).

[6] Yang Bo; Research Overview on the Evaluation of Wetland in China; Ecology; 2004(4). 